ship and dictation of every kind that is outside of the great nursing body. Remember that the leaders are only as strong as their backers, and let us not lose time by petty differences.

\title{
AN INTERESTING SITUATION IN MASSACHUSETTS
}

IN no State where registration is under consideration are the problems so difficult of solution and almost ludicrous as in Massachusetts. During the month developments have been interesting. We explained in the January number something of Dr. Alfred Worcester's position in regard to State registration.

- In the August; 1902, issue of the Journal we published an address delivered by Dr. Alfred Worcester to the nurses of the Long Island Hospital of Boston, entitled "Is Nursing Really a Profession?"

One gathers the impression from this paper that Dr. Worcester is cordially in favor of nurses managing their own affairs. On page 911 we find the following:

"In recognition of the invaluable assistance given by the sister profession, the busiest physicians and surgeons give unsparing every possible aid in the instruction of student nurses. It is true they look forward with hopeful anticipation to the time when they shall be relieved of much of this work by nurses who, having mastered both the science and the art of nursing, shall undertake all the teaching of their successors.

"This thought leads me to point out that one of the obstacles to the recognition of nursing as a profession is this temporary dependence upon the medical profession for teaching in schools for nurses. But already it is plain that only the comparatively unimportant science can be taught by physicians, and that the art of nursing can be taught only by nurses. And now that highly educated women are entering the profession, we shall surely soon have nurses who are at least equally able to teach the science upon which the art of nursing depends.

"So much for the teaching test.

"Another closely allied characteristic of a true profession is the sharing with all associates every professional advantage. The lawyer, the clergyman, and the physician delight in giving brotherly help to their fellows. They have associations and meetings for sharing their discoveries and regulating their professions.

"Can modern nurses stand this professional test? I wish I could answer more positively in the affirmative. There are many hopeful signs. Associations of nurses are forming, nursing journals are at last under the control of nurses, books upon nursing by nurses are increasing, more interest is being shown by nurses in the regulation of their profession. But it must be admitted that progress in this direction has been provokingly slow. The modern nurses too often have followed their predecessors in unprofessional ways. They have not helped each other; 
they have not given cordial support to the nursing associations and journals that are struggling to advance the profession. They have even allowed themselves to be sent out to service by registries controlled not by nurses and conducted not by nurses' interests, but for the pecuniary gain of others. In these registries were filed away criticisms of the nurses, perhaps containing reflections upon their characters, which the nurses themselves might never see, but which, nevertheless, determined their careers. So long as nurses meekly submit to such servant intelligence-office treatment it will be difficult to maintain that they appreciate their professional privileges and obligations. However, in all those ways wherein modern nurses have failed to assume full professional responsibilities there is improvement already visible; and, after all, it must not be forgotten that there has as yet been very little time for the metamorphosis of nursing.

"We who belong to a profession centuries old may well be slow to criticise a profession that has not yet outlived its founders."

This address was given several years ago, before the nurses of Massachusetts had organized for the first great step towards making "nursing really a profession." One naturally expected to find Dr. Worcester a leading figure in this movement, aiding by his political, professional, and social influence the effort of the nurses of his State to realize some of the ideals that he had advocated.

But no! During the campaign last winter he sat so skilfully " on the fence" that no one knew exactly where to find him. This year he was invited to speak at the State meeting on January 12. He evaded this invitation. Then he was asked to fix his own date when the nurses might hear his views on State registration. This really was a cruel move on the part of the State association committee, as it forced him to openly acknowledge that he was opposed to the State registration of both physicians and nurses.

Dr. Worcester, with some kindred spirits, has sent the following circular letter to the medical superintendents of the hospitals of New England and others. This letter is dated December, 1904, and reads as follows :

"It is proposed to form an association of all who are interested and actively engaged in advancing the profession of nursing; and it is desired to secure the coöperation of every training-school for nurses in New England.

"In no sense is it proposed to antagonize or to supplant existing associations of graduate nurses and of training-school superintendents, but rather to supplement their laudable efforts for the advancement of their profession by enlisting for this purpose the medical and lay instructors, the managers and trustees, and all other benefactors of nurses' training-schools. 
"It is confidently expected that such an association will bring about more uniform methods of training, higher standards of education, more effective coöperation between the medical and the nursing professions, and, finally, more serviceable relations between nurses and such institutions and families as need their services.

"It is hoped that in such an association it will be possible to arrange for the interchange of courses of instruction for student nurses, for their broader education, and also advanced courses in the specialities of nursing.

"It is also hoped that some central Examining Board may be devised which shall, by giving graded certificates, guarantee the fitness of nurses, who are recommended by their schools, in the different departments of nursing. In connection with this service, such an Examining Board might also assist training-schools to provide such instruction as will fit their students for the association's endorsement.

" Such work as proposed has been of great service in Holland during the past thirty years. It is further hoped that a weekly nursing journal may be established, under the auspices of the association, which shall contain lectures upon nursing subjects as well as the locally interesting nursing news.

"And perhaps it may also be hoped that the association will maintain a New England registry of nurses, which shall serve to unite existing registries, and to help all nurses who hold the association's certificates to find employment wherever they may be living as well as in the immediate neighborhood of the schools were they were trained.

"It is proposed to hold a conference in Boston early in the coming year for the consideration of these purposes, and for the organization of the association.

"If the idea meets with your approval, and if you would like to help in such a movement, will you kindly so notify anyone of the undersigned provisional committee.

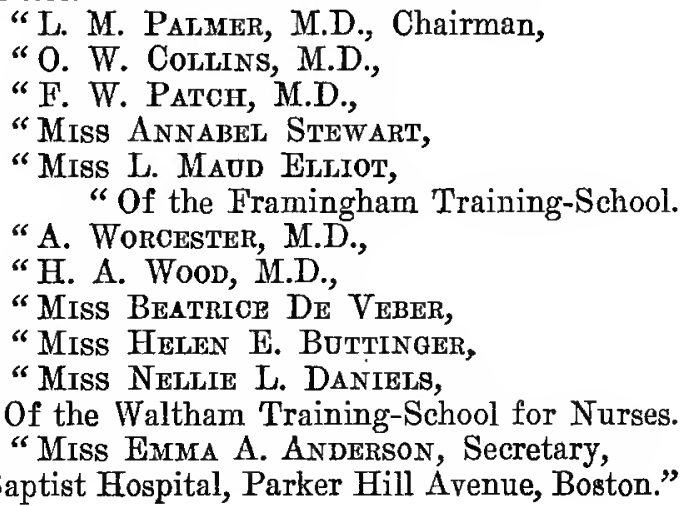

While this circular is very skilfully worded, no one of the initiated can fail to see that it is an effort for organized opposition to State registration. And why? Because, as we stated last month, the graduates of 
the Waltham Training-School, of which Dr. Worcester is the proprietor, are excluded from membership in the Massachusetts State Nurses' Association and in all the national nursing organizations of the country because of the limited training in a hospital, and the Framingham school belongs in the same class.

This circular states in one place that the new association is not intended to "supplant the existing associations of graduate nurses and of training-school superintendents, but to supplement their laudable efforts for the advancement of their profession by enlisting for this purpose the medical and lay instructors, the managers and trustees, and all other benefactors of nurses' training-schools." It would have been more in accord with our idea of modesty if Dr. Worcester had waitcd until the "graduates and superintendents" asked him to intercede for them.

Farther on it proposes to establish a central Examining Board which shall give graded certificates, etc.

What need of such an Examining Board when the "existing" State associations of nurses of New England shall through their "laudable" effort have secured the State registration of trained nurses, with a Board of Nursc Examiners in each State, who shall be legally authorized to determine the "fitness" of nurses?

In the refercnce to nursing conditions in Holland, one is inclined to believe that it is intended by Dr. Worcester and his confreres to introduce into New England the Old World custom of the absolute control of the graduates by the hospitals that amounts to a condition almost of slavery, and against which is slowly developing revolt for personal liberty among nurses in Great Britain, Denmark, Holland, and Germany. Miss Dock's report on the Dutch Nursing Association in this issue certainly does not convey the idea that conditions in Holland have reached a high state of perfection under the thirty-years' rule that is referred to in the circular.

There is only one interpretation to put upon this remarkable proposition. It is an effort to defeat the registration movement in Massachusetts, led principally by the proprietors and graduates of disqualified nursing schools.

If the nurses of Massachusetts and all the States of New England can be depended upon to stand solidly together as a unit in opposition to this self-appointed Czar of the nursing profession, he cannot succeed in his efforts for their "upbuilding," but if they are timid or if there are traitors in the ranks, which we already have reason to believe there are, it may take years to overcome the mischief that he may do.

Miss Anderson, the secretary of the committee which has issued the call for a meeting for the organization of the new association, is a grad- 
uate of the Training-School of the Massachusetts General Hospital, and she was at one time the secretary of the Alumnæ Association. She is the superintendent of a small hospital the graduates of which are disqualified from membership in the Massachusetts State Nurses' Associationfor one reason, that the school uses its pupils as a means of earning money for the hospital. Instead of joining forces with the nurses of her State in an effort to control this abuse, we find her in the ranks of the obstructors.

Dr. Howard, superintendent of the Massachusetts General Hospital, and Miss Dolliver, superintendent of the Training-School, have declined to endorse this movement.

Miss M. M. Riddle, superintendent of the Newton Hospital and president of the Nurses' Associated Alumnæ of the United States, has refused to have any part in the new association, and we cannot believe that either nurses or doctors who possess the true professional spirit will take any part in an organization so opposed to State registration.

\section{PROGRESS OF STATE REGISTRATION}

DuRING the past month we have seen copies of the bills for registration prepared by the California, Colorado, Indiana, Pennsylvania, Connecticut, Massachusetts, and District of Columbia Nurses' Associations. A number are already in the hands of the legislators and all that become laws will be published in full in these pages at the end of the season.

The standards of some of these bills are exceptionally fine. All ask for a Nurse Board of Examiners to be appointed from nominations from the State associations. In California and Colorado a High-School diploma or its equivalent with three-years' general hospital training is required.

California and Pennsylvania have the support of the State Medical Associations and leading medical journals. Connecticut will undoubtedly have such endorsement, as the leading medical men are in sympathy with the morement. Conditions seem to be in a measure doubtful in Massachusetts, Indiana, and the District of Columbia, owing to the conservative medical attitude in nursing affairs in these places.

The next three months will be most exciting in all States where legislation is in progress, and in just the proportion that nurses are active and united good results must follow.

In legislation the support from the small cities and towns counts for more than the activity in big cities. Every doctor, every legislator, 